\title{
REVISÃO SISTEMATIZADA DA LITERATURA CIENTÍFICA NACIONAL ACERCA DA HISTÓRIA DO HIV/AIDS
}

\author{
Ítalo Fernandes,' Maria Alves de Toledo Bruns² \\ SYSTEMATIC REVIEW OF THE NATIONAL SCIENTIFIC LITERATURE ABOUT \\ THE HISTORY OF HIV / AIDS \\ REVISIÓN SISTEMÁTICA DE LA LITERATURA CIENTÍFICA NACIONAL SOBRE \\ LA HISTORIA DEL VIH / SIDA
}

\begin{abstract}
Resumo: Cerca de 37 milhões de pessoas no mundo, sendo 966 mil no Brasil, em particular, convivem com o vírus da imunodeficiência humana/síndrome da imunodeficiência adquirida (HIV/AIDS). A doença teve seus primeiros registros no início da década de 1980. Dois pesquisadores são destaque na descoberta do vírus. Os médicos e pesquisadores Robert Charles Gallo e Luc Montagnier. Partindo dessa evidência, emergiu a questão norteadora: "o que a literatura científica nacional oferece sobre a história do HIV/AIDS?". Para responder essa indagação foi realizada uma revisão sistemática e meta-análise nas bases de dados: SciELO e BDTD. Resultados: foram analisados oito estudos na íntegra, posteriormente categorizados por eixos temáticos: (I) A doença na interface com o estigma; (2) A doença na interface com as políticas de saúde pública; e (3) A doença na interface com a mídia. Fica evidente que há um grande acervo de pesquisas sobre HIV/AIDS no Brasil. Lamentavelmente, nesses estudos analisados, em nenhum momento o diálogo familiar é apontado como forma de resposta da epidemia do vírus. Portanto, é importante considerar, que as matrizes de sentido, família e escola, devem assumir um diálogo amoroso e esclarecedor, pautado em evidências e comprometido com a saúde sexual contemporânea.
\end{abstract}

Palavras-chave: HIV/AIDS; educação sexual; revisão sistematizada.

Abstract: About 37 million people in the world, 966 thousand of whom in Brazil, in particular, live with the human immunodeficiency virus / acquired immunodeficiency syndrome (HIV / AIDS). The disease had its first records in the early 1980s. Two researchers are prominent in the discovery of the virus. Doctors and researchers Robert Charles Gallo, and Luc Montagnier. Based on this evidence, the guiding question emerged: "what does the national scientific literature offer about the history of HIV / AIDS?". To answer this question, a systematic review and meta-analysis was carried out on the databases: SciELO and BDTD. Results: 8 studies were analyzed in full. Subsequently categorized by thematic axes: (I) Disease at the interface with stigma; (2) The disease at the interface with public health policies; and (3) The disease at the interface with the media. It is evident that there is a large collection of research on HIV / AIDS in Brazil. Unfortunately, in these studies analyzed, family dialogue is never mentioned as a way of responding to the virus epidemic. Therefore, it is important to consider that the matrices of meaning, family and school, must assume a loving and enlightening dialogue, based on evidence and committed to contemporary sexual health.

Keywords: HIV/AIDS; sexual education; systematic review.

Resumen: Cerca de 37 millones de personas en el mundo, 966 mil de las cuales en Brasil, en particular, viven con el virus de inmunodeficiencia humana / síndrome de inmunodeficiencia adquirida (VIH / SIDA). La enfermedad tuvo sus primeros registros a principios de la década de 1980. Dos investigadores se destacan en el descubrimiento del virus. Los médicos e investigadores Robert Charles Gallo y Luc Montagnier. A partir de esta evidencia, surgió la pregunta orientadora: “¿Qué ofrece la literatura científica nacional sobre la historia del VIH / SIDA?". Para responder a esta pregunta se realizó una revisión sistemática y un metaanálisis de las bases de datos: SciELO y BDTD. Resultados: Se

\footnotetext{
' Mestre em Educação Sexual pela Universidade Estadual Paulista (UNESP) - campus Araraquara. E-mail: italo_fernandesfernandes@hotmail.com

2 Pós-doutorado em Linguística pela Universidade de São Paulo (USP) - campus Ribeirão Preto. Docente do Programa de Pós-Graduação em Educação Sexual da Universidade Estadual Paulista (UNESP) - campus Araraquara e do Programa de Pós-Graduação em Psicologia do Departamento de Psicologia da Faculdade de Filosofia, Ciências e Letras da USP, Campus Ribeirão Preto. E-mail: toledobruns@gmail.com.br
} 
analizaron en su totalidad 8 estudios. Posteriormente categorizados por ejes temáticos: ( I) Enfermedad en la interfaz con el estigma; (2) La enfermedad en la interfaz con las políticas de salud pública; y (3) La enfermedad en la interfaz con los medios. Es evidente que existe una gran colección de investigaciones sobre el VIH / SIDA en Brasil. Lamentablemente, en estos estudios analizados nunca se menciona el diálogo familiar como una forma de responder a la epidemia del virus. Por tanto, es importante considerar que las matrices de sentido, familia y escuela, deben asumir un diálogo amoroso y esclarecedor, basado en la evidencia y comprometido con la salud sexual contemporánea.

Palabras clave: VIH/SIDA; educación sexual; revisión sistemática.

\section{Introdução}

Este artigo almeja apresentar o que a literatura científica nacional oferece sobre a história do HIV/AIDS. Para isso, situamos nosso fenômeno no cenário do mundo contemporâneo. Essa realidade é composta de profundas e significativas transformações no estilo de vida de cada pessoa no que tange às suas relações sexuais e afetivas. “Isto significa dizer que a 'práxis' sexual e afetiva está submetida a regras, normas e estatutos, repressivos ou não, que são elaborados e reelaborados no decorrer da história" (BRUNS; FERNANDES, 2019, p. 50).

Nesse cenário, por intermédio de respostas científicas, burocráticas e de militância, que contemplaram saberes de diversas áreas da ciência, integrando aspectos sociais, políticos, econômicos e culturais da sociedade, foi construída a trajetória da AIDS (BARATA, 2006; BARROS; VIEIRADA-SILVA, 2016; BASTOS et al., 1993; MARQUES, 2002; SANABRIA, 2016; SANTOS, 1999; WESTRUPP, 1997).

As primeiras investigações sobre o agente etiológico da doença ocorreram no início da década de 1980. Autores como Forattini (1993), Duarte (1995) e Santos (1999) descrevem a primeira década da doença como fundamental na descoberta e formulação das respostas iniciais à epidemia da AIDS no mundo.

Nesse contexto, dois pesquisadores e suas respectivas equipes são destaque na descoberta do vírus etiológico da AIDS, o HIV. O médico e pesquisador Robert Charles Gallo, do National Cancer Institute, nos Estados Unidos da América, e o médico e pesquisador Luc Montagnier, do Instituto Pasteur, em Paris, na França (DUARTE, 1995; SANTOS, 1999).

A segunda década da epidemia da AIDS (19902000) foi marcada pelo aprimoramento e grandes avanços das condutas terapêuticas. Considerando os processos ocorridos a partir do final da década de 1980 até 1996, que tratavam da introdução e substituição do tratamento anti-HIV monoterápico para terapia combinada, deu-se início a uma nova era. A terapia combinada é a "combinação de várias drogas [que] bloqueia a multiplicação ou a entrada do vírus" no corpo humano (MARQUES, 2002; SANTOS, 1999).
Diante do caminho percorrido por esses autores, era de se supor que a epidemia estivesse controlada. Contudo, atualmente, fica evidente em estudos da epidemia da AIDS que nas duas décadas que se sucederam (2000-2010/2010-2020) o número de pessoas que têm convivido com o vírus do HIV aumentou (BRASIL, 2019).

Partindo dessa evidência, emergiu a questão norteadora: "o que a literatura nacional oferece sobre a história da AIDS?". Focamos nos eixos temáticos que emergiram da revisão sistematizada da literatura nacional, realizada de janeiro a março de 2020, nas bases de dados Scientific Electronic Library Online (SciELO) e Biblioteca Digital Brasileira de Teses e Dissertações (BDTD). Foram esses eixos: (I) A doença na interface com o estigma; (2) A doença na interface com as políticas de saúde pública; e (3) A doença na interface com a mídia. A partir desse pano de fundo do fenômeno que propomos compreender, tecemos a história do HIV/AIDS.

\section{Método}

O presente estudo foi realizado por meio do método de revisão sistemática e meta-análise de Uman (20II apud ZERBINATI; BRUNS, 20I7, p. 78) - eleito por sua capacidade de responder a uma pergunta utilizando a identificação, seleção e avaliação dos conteúdos encontrados. Um trajeto composto por oito passos:

(I) Formulação da pergunta; (2) Definição de critérios de inclusão e exclusão; (3) Estratégia de busca e localização dos estudos; (4) Seleção dos estudos; (5) Extração dos dados; (6) Avaliação da qualidade do estudo; (7) Análise e interpretação dos resultados; (8) Discussão e Considerações finais.

A busca aconteceu no período de janeiro a março de 2020, simultaneamente em dois bancos de dados eletrônicos, a saber: SciELO e BDTD, nos quais foram inseridos os descritores cuja combinação: "AIDS or hiv", "origem ou descoberta ou história", "epidemia". Para inclusão, os critérios estabelecidos foram: (I) a produção acadêmica deve estar disponível integralmente e (2) pertencer à base de dados nacional, sendo excluídos todos os estudos duplicados e que fogem à temática (NUNES, 
20I5). Na sequência, os resumos foram lidos e analisados para posterior leitura na íntegra. Surgiram dessa etapa os eixos temáticos que possibilitaram a investigação das peculiaridades de cada estudo utilizado, agregando fatores para a análise e discussão.

\section{Resultados}

De acordo com a Figura I, fluxograma de seleção dos estudos e extração dos dados, foram encontrados: 217 (Scielo $n=49 ;$ BDTD $n=168$ ) estudos. Nessa etapa, conforme os critérios de inclusão e exclusão, foram removidos $n=209$, possibilitando, ao final da seleção, o uso de 8 , dentre os quais artigos, dissertações e teses com texto completo disponíveis on-line.

Figura I - Fluxograma de identificação, exclusão e elegibilidade final dos artigos para revisão sistematizada.
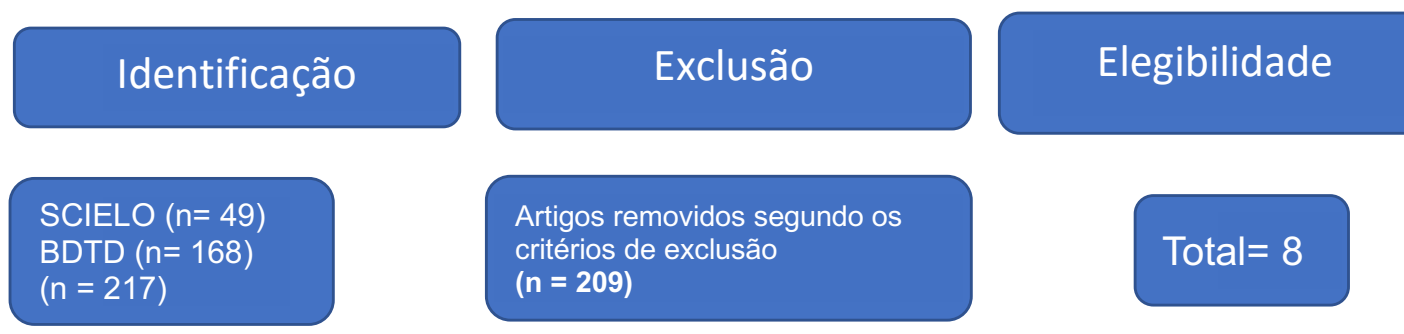

Artigos removidos segundo os

critérios de exclusão

( $n=209)$

\section{Total $=8$}

Fonte: elaborada pelos autores (202I).

Quadro I - Categorização dos estudos eleitos para análise $(\mathrm{n}=8)$

\begin{tabular}{|l|l|l|}
\hline Eixos Temáticos & Descrição & Referências \\
\hline $\begin{array}{l}\text { A doença na interface com } \\
\text { o estigma }\end{array}$ & $\begin{array}{l}\text { Os autores fazem uso de estudos das diversas } \\
\text { áreas do conhecimento para inferir que houve um } \\
\text { senso moral, preconceituoso e estigmatizante na } \\
\text { construção da história da epidemia e a mudança do } \\
\text { perfil do infectado. }\end{array}$ & $\begin{array}{l}\text { DUARTE (20I8); SANABRIA } \\
(20 \text { I6). }\end{array}$ \\
\hline $\begin{array}{l}\text { A doença na interface } \\
\text { com as políticas públicas } \\
\text { brasileiras }\end{array}$ & $\begin{array}{l}\text { Neste eixo, os autores analisam a história das } \\
\text { políticas públicas de AIDS no Brasil, desde seu } \\
\text { aparecimento no país. }\end{array}$ & $\begin{array}{l}\text { BARAROS; MARQUES (2002); } \\
\text { SILVA (20 I6); })\end{array}$ \\
\hline $\begin{array}{l}\text { A doença na interface com } \\
\text { a mídia }\end{array}$ & $\begin{array}{l}\text { Estes estudos buscaram apresentar a construção } \\
\text { da história da AIDS a partir da mídia. }\end{array}$ & $\begin{array}{l}\text { ARRAES (20I5); BARATA } \\
\text { (2006); SILVA (20I2). }\end{array}$ \\
\hline
\end{tabular}

Fonte: elaborada pelos autores (2021).

\section{A doença na interface com o estigma}

No estudo de Sanabria (2016), o autor objetivou mostrar que suposições sobre comportamentos sexuais, raça e nacionalidade estiveram presentes desde o início do conhecimento sobre a AIDS, estabelecendo a existência de grupos-de-riscos, categorias de exposição e vulnerabilidade ao vírus. Desde as primeiras discussões sobre a origem da doença, foram produzidos, marcados e reforçados, de forma irreversível, o estigma e a discriminação, e, consequentemente, o sujeito infectado pelo vírus HIV/AIDS.

O termo AIDS foi utilizado pela primeira vez no ano de 1982, momento em que ainda era desconhecido o agente causador da doença. Foi por intermédio da publicação do Centers for Disease Control (CDC), nos Estados
Unidos, que ocorreu a classificação para denominar a epidemia que estava acometendo a população de jovens homens homossexuais dos grandes centros urbanos de Los Angeles, Nova York e São Francisco. A partir dos primeiros diagnosticados na década de 1980, viver com HIV/AIDS era sinônimo de uma prática sexual excessiva, desviante e desregrada. Essa construção social da AIDS, estabelecida à luz de conceitos preconceituosos e estigmatizantes, foi ancorada na moral dominante, patriarcal e heteronormativa da sociedade.

Como resultado dessa construção, aos homossexuais foi atribuído "estar associado a AIDS", relação que "passou a significar muito mais do que apenas ser afetado pelo HIV; significa(va) também ser impuro, indesejável 
entre outros, ser culpado e causar escândalo e medo" (SANABRIA, 2016, p. 5).

Duarte (2018, p. 42), em sua tese A AIDS tem um rosto de mulher: discursos sobre o corpo e a feminização da epidemia, apresentou e propôs uma reflexão a respeito da mudança no perfil das pessoas que convivem com a doença, pois "[...] é possível dizer que o perfil da AIDS se distanciou ao longo dos anos de suas vítimas iniciais e se aproximou lenta e progressivamente das mulheres".

Uma pausa importante se faz necessária para uma compreensão "macro" do fenômeno da feminização da doença, evitando assim possíveis desvios que possam tendenciar essa análise. $A(r e)$ configuração social da doença foi "[...] silenciosa, discreta, paciente, privada, doméstica. Ela aconteceu sem alarde, sem holofotes, e jamais alcançou a projeção necessária para desconstruir completamente a metáfora da "praga gay"' (DUARTE, 2018, p. 43).

No processo de construção sócio-histórico da epidemia da AIDS, inúmeras produções retratam como verdades absolutas as pesquisas iniciais, que massificaram intensamente a transmissão por via sanguínea e as práticas sexuais dos homossexuais, camuflando e subvertendo o cenário real da epidemia já naqueles anos.

Nesse contexto, Paiva (1999, p. 7) descreve que a AIDS "passa a ser compreendida como uma doença de homens e mulheres", sem distinção de orientação sexual, gênero, ou classe social. Dessa forma, podem surgir questões sobre como essa mulher se infectou, sendo a doença, a princípio, relacionada as relações homossexuais?

$$
\text { Para Paiva (1999, p. 10), }
$$

o vírus da AIDS pode ser encontrado tanto na ejaculação masculina quanto na lubrificação, na ejaculação feminina e na menstruação, que contém linfócitos T4 que podem conter o HIV. Portanto, uma mulher pode se contaminar com os homens (hetero e bissexuais) ou com mulheres (homo e bissexuais).

Esse estudo sustenta o resultado da tese de Duarte (2018). A autora desvelou que ao longo de duas décadas (1980-2000) o perfil da doença mudou e com ele mudou também o estigma. Suas colocações apresentam outro perfil, logo, outras vulnerabilidades, pois ser mulher e conviver com HIV é duplamente estigmatizante, uma dupla "punição".

Partindo da premissa de que as mulheres estiveram excluídas das políticas de saúde pública e da produção de conhecimento acerca da população vulnerável ao HIV/AIDS, Lúcio e outros (2019), no estudo intitulado "Saúde sexual da mulher lésbica e/ou bissexual: especificidades para o cuidado à saúde e educação sexual”, apresentaram, por intermédio de uma revisão integrativa da literatura, a fragilidade e marginalização dessa população no acesso à informação e educação sexual de qualidade como também desmistificou concepções errôneas que existem acerca da sexualidade dessa população.

Diante desse percurso, estudos atuais acerca da epidemiologia geral, e de HIV/AIDS em particular, tratando do atual perfil da infecção, trazem dados do Boletim Epidemiológico de 2019, do Ministério da Saúde, que evidenciam uma tendência de crescimento do HIV, o que pode ser considerado um rebote da epidemia. No Brasil, esses dados, com base nos últimos dez anos (2009-20 I9), retratam essa tendência entre adolescentes, jovens e adultos do sexo masculino, nas faixas etárias de 15 a 19 anos, 20 a 24 anos, 25 a 29 anos e entre 60 anos ou mais (BRASIL, 2019).

\section{A doença na interface com as políticas de saúde pública}

Marques (2002), em seu artigo "Saúde e poder: a emergência política da AIDS/HIV no Brasil", analisou a trajetória da reposta brasileira à epidemia da AIDS no país. Com base em estudos, documentos e fontes orais, a autora propôs a compreensão dessa história em cinco períodos: (I) "Pré-história da AIDS/HIV no Brasil"; (2) "I 983 a 1986: a AIDS/HIV torna-se uma realidade brasileira"; (3) "I987 a 1989: o programa nacional de AIDS/HIV toma forma"; (4) "A era Collor"; e (5) "A partir de 1993: uma nova era". O resultado de seu estudo revelou que é possível afirmar que "[...] a AIDS/HIV inaugurou, considerando todas as questões apresentadas, uma nova forma de construir políticas de saúde pública no Brasil diante de eventos de saúde coletiva" (MARQUES, 2002, p. 63).

No estudo de França (2008), a autora apresentou como e porquê o Brasil se tornou referência internacional no combate à epidemia da AIDS nos primeiros anos da doença. Consultando relatos médicos e de outros profissionais da saúde, juntamente com buscas que realizou na literatura, a autora teceu a trajetória dessa construção das políticas públicas no Brasil. Os resultados foram: a doença AIDS/HIV surgiu em um momento de transformações políticas no país - período pós-ditadura militar, que se seguiu nos anos de 1984- 1985 com a transição democrática do poder, novas estruturas e alianças emergindo no país, e no estado de São Paulo, em particular. Essas novas conjunções favoreceram a indicação de grandes nomes de sanitaristas, o que corroborou com a reforma sanitária e, consequentemente, com a criação do Sistema Único de Saúde (SUS). Dessa forma, as políticas de saúde pública no combate à epidemia da AIDS obtiveram sucesso por criarem elos compartilhados no âmbito médico, político, educacional e sociocultural.

No estudo sócio-histórico de Barros e Vieira-daSilva (2016), as autoras buscaram tecer a história das políticas públicas brasileira sobre HIV/AIDS a partir da análise delas próprias na primeira década da doença no país (198I-1989). Os resultados foram: os agentes sociais, o 
campo médico e os governos, no âmbito político nacional e do estado de São Paulo, em particular, foram decisivos para que o país fosse reconhecido internacionalmente como exemplar. No contexto inicial, as ações articuladas por importantes nomes da ciência sanitarista e governamentais priorizavam a prevenção. Já no final da década de 1980, a criação do Sistema Único de Saúde (SUS) e, consequentemente, o acesso ao tratamento público e gratuito passou a integrar esse plano de controle.

Esse "espaço-AIDS" criado no Brasil em reposta à epidemia, antes estrangeira e agora coletiva, foi constituído e construído nos espaços militantes, científico e burocrático. Os agentes correspondentes a cada uma das esferas sociais citadas, articularam-se na criação desse espaço, provocando o estabelecimento no ano de 1985, do Programa Nacional de Doenças Sexualmente Transmissíveis (DST) e AIDS (PNAIDS). "As primeiras medidas adotadas pelo MS (Ministério da Saúde) foram vigilância epidemiológica, educação e informação sanitária, testagem voluntária e caracterização de uma epidemia que afetava a toda a população" (BARROS; VIEIRA-DA-SILVA, 2016, p. 7).

Conforme verificado pelas autoras, diante desse cenário de redemocratização do país, torna-se inegável o importante papel desempenhado pelo SUS. Esse programa criado a partir da publicação da Constituição Federal (Brasil, 1988), que traz no seu artigo 196, da seção "Saúde":

A saúde é direito de todos e dever do Estado, garantido mediante políticas sociais e econômicas que visem à redução do risco de doença e de outros agravos e ao acesso universal e igualitário às ações e serviços para sua promoção, proteção e recuperação.

Dessa forma, ao prever acesso universal e gratuito aos serviços de saúde no país, o programa cumpriu, de certa maneira, com o que está estabelecido nas diretrizes de direitos humanos. Seria um erro, porém, atribuir somente ao Ministério da Saúde o sucesso alcançado ao longo da história das políticas de saúde pública de HIV/ AIDS no Brasil. Esse se fez na articulação dos Ministérios da Saúde e da Educação, firmada desde o ano de 1995, quando se criou um ambiente favorável à implantação do "Projeto Escolas", cujas ações foram de 1994 a 1999. No ano seguinte, em 2000, o projeto passou a se chamar "Salto para o Futuro". Em 2003, é lançado na cidade de Curitiba, no estado do Paraná, o projeto "Saúde e prevenção nas escolas" - reformulado em 2005, mesmo ano em que houve a "consolidação da política de prevenção das DST/AIDS nas escolas" (BRASIL, 2006).

Sob essa ótica, ganha particular relevância a articulação entre as matrizes de sentidos propostas por Trindade e Bruns (2003, p. 88) em sua obra intitulada Sexualidade de jovens em tempos de AIDS.

O que constatamos, ao longo deste estudo, é que a vida humana implica riscos, contradições e possibili- dades e que, em especial, no que diz respeito à sexualidade, os riscos mostram-se bastante presentes na vida dos jovens. Isto sem falarmos dos riscos nas demais fases de nossa existência. Pensamos, neste sentido, que o universo social, por meio das escolas, famílias, dos meios de comunicação, pode e deve contribuir para o preparo dos jovens na conscientização de seu envolvimento e comprometimento em sua vida afetiva e sexual.

A partir dessa premissa, faz-se necessário contextualizar ao leitor que nos acompanha neste estudo, que mesmo em meio a avanços e retrocessos nas políticas de saúde pública, como também na área da educação, a AIDS trouxe visibilidade à comunidade homossexual da década de 1980-1990. Trevisan (2018) refletiu no capítulo "O vírus, nosso irmão" que faz parte da sua obra Devassos no Paraíso: a homossexualidade no Brasil, da colônia à atualidade, que "graças" a AIDS é que a população LGBT ganhou voz, e passou a ser lembrada desde pequenos diálogos no mundo doméstico das famílias, como em manchetes de grande alcance, nacional e internacional.

No caso específico dos homossexuais, que por muitos anos estivemos na linha de frente da epidemia, o HIV fez ainda o milagre de nos revelar ao mundo. A contragosto ou não, as primeiras páginas dos jornais estamparam repetidamente que nós existimos. Se a visibilidade é um tema político fundamental, então o vírus nos deu a maior visibilidade possível, num curtíssimo prazo: aquilo que o movimento homossexual não conseguiria em duas décadas o vírus fez em poucos anos de peste. Em função do vírus, hoje já se sabe amplamente onde e como trepamos [...] tenho a fantasia de que, uma vez superada a barreira imediata do vírus, as pessoas estarão muito mais disponíveis do que as gerações anteriores para a prática homossexual. Bem ou mal, com mais ou menos dor, saímos do armário, nestes tempos de enganosa permissividade (TREVISAN, 2018, p. 619-620).

Diante do exposto, é fundamental estabelecer um diálogo interdisciplinar capaz de conectar as matrizes de sentido para construir uma consciência subjetiva amorosa com a própria saúde sexual. Atualmente, não temos uma estrutura política e social que favoreça essa educação sexual emancipatória.

\section{A doença na interface com a mídia}

O estudo de Barata (2006) buscou analisar de maneira qualitativa a forma como a AIDS foi apresentada aos brasileiros. Como recorte de sua pesquisa, a autora fez uso do recurso televisivo, explorando as notícias divulgadas sobre a doença no programa Fantástico entre os anos de 1983 e 1992. Os resultados foram: por ser pioneiro em apresentar a doença na mídia, o programa foi responsável por introduzir e preencher gargalos nas 
discussões a respeito da doença da AIDS. Nesse contexto, a mídia assim como outros meios de acesso à informação foi responsável por criar, fomentar e disseminar "[...] as metáforas, mitos, estereótipos e preconceitos da AIDS", os quais "[...] refletem e reforçam o inconsciente coletivo" (BARATA, 2006, p. 145).

Contrapondo a concepção negativa da mídia no texto da autora, pesquisas atuais acerca da epidemia do HIV/AIDS no cenário contemporâneo apontam a mídia como importante estratégia de combate e controle da epidemia no país.

Partindo da premissa positivista do uso das mídias na resposta à epidemia, em sua dissertação de mestrado intitulada: AIDS na cibercultura: a midiatização da doença nas redes sociais online do Ministério da Saúde, Silva (2012) procurou expor a maneira como a doença é retratada nas mídias sociais do governo federal brasileiro. Como seria impossível classificar todas as redes sociais existentes na atualidade, a autora definiu Facebook, Twitter, Orkut, Flickr, Formspring, YouTube, Slideshare, Soundcloud, e o Blog como bases para seu estudo.

Os resultados obtidos foram: mesmo diante do grande acúmulo de estudos que focam a doença, AIDS/ HIV ainda continua sem cura. Contudo, na atualidade foi possível desvincular a doença da morte e associá-la à vida, uma trajetória proporcionada pelo tratamento antirretroviral e pela terapia combinada. Para a autora, "desde que foi descoberta, no início da década de 1980, a AIDS é midiatizada de forma a alertar a população sobre os perigos da contaminação pelo vírus HIV". Com o surgimento do espaço cibercultural, Silva (2012) afirma que o discurso mudou desde as primeiras publicações nas redes oficiais do Ministério da Saúde do Brasil. No período analisado pela autora (1983-1992), esse discurso se manteve focado no diagnóstico precoce e no combate ao preconceito. Concluiu-se que "o órgão máximo da saúde brasileira" precisava reforçar sua preocupação e atenção em publicações fora de datas sazonais, como no Carnaval e no dia primeiro de dezembro, conhecido internacionalmente como o Dia Mundial de Luta contra a AIDS (SILVA, 2012, p. I25).

O estudo de Arraes (2015) buscou analisar campanhas de prevenção ao risco do HIV/AIDS, desde a década de 1980, em vídeos e publicações oficiais do Ministério da Saúde para responder a sua questão norteadora: "como em todos esses anos, mesmo com informações e acesso ao preservativo, os sujeitos escolhem não utilizar o preservativo nas relações sexuais?". Como resultado, ela obteve que as publicações não atingiam todas as populações. $O$ discurso presente nas campanhas tentava padronizar os comportamentos sexuais da população, culpabilizando os sujeitos já infectados e não considerando a diversidade de segmentos, logo, de concepções variadas do que é risco. A autora não classifica essas campanhas como estratégias errôneas durante a trajetória do combate ao vírus no país. Contudo, deixa claro que o subjetivo do sujeito e seu meio devem ser considerados no momento de elaboração dessas campanhas (ARRAES, 2015, p. 298).

Diante desses fatos apresentados por Arraes (2015), não se pode ignorar o fator estigmatizante das campanhas publicitarias da época. Para efeito de informação, essas respostas midiáticas de prevenção consideraram por um longo período, o vírus HIV e a doença AIDS como exclusiva da população homossexual. Assim, homens que não se consideravam gays, mas realizavam práticas sexuais com outros homens, acreditavam estar isentos de riscos a infecção. Foram essas fronteiras imaginárias de "população geral" diferente desses homens que tinham relações sexuais com outros homens, que propiciou o aumento dos casos de infecção heterossexual e concomitante à infecção de mulheres. Por isso, estudiosos da área adotaram a terminologia "homens que fazem sexo com homens (HSH)" a fim de incluir essa categoria nos grupos de risco. Mora, Brigeiro e Monteiro (2018), classificam esse cenário, por meio das mídias e da produção científica, como "concepções etnocêntricas e de cunho sexista e homofóbico".

\section{Considerações finais}

A discussão levantada na análise, sugere que ao longo da trajetória da doença, há muitos estudos que tratam da AIDS e de seu agente etiológico HIV. Portanto, a doença tem sua história construída por intermédio da ciência médica, epidemiológica, viral ou social, com alicerces na política de cada sociedade. Por essa razão, tem particular relevância que estudos futuros possam desvelar os horizontes da história do vírus HIV, pela perspectiva de quem o conhece de perto, ou seja, do mundo-vida do sujeito que experiencia esse viver.

Não se trata apenas, de realizar levantamentos, incluir dados estatísticos, quantificar essa camada social, ou de historicizar essas relações. Mesmo porque, debate-se que exista na atualidade populações-chave, que se encontram em maior vulnerabilidade de exposição ao vírus. Partindo da premissa, que a doença está presente nessas populações, fazendo parte do cotidiano de jovens, entre as faixas etárias de 15 a 29 anos, como também na população de 60 anos ou mais, é correto afirmar que os esforços de pesquisadores devem estar voltados a compreender esse fenômeno.

Lamentavelmente, nesses estudos analisados, em nenhum momento da história do HIV/AIDS, o diálogo familiar é apontado como forma de resposta da epidemia do vírus. O silêncio nos lares, acerca de uma sexualidade saudável, como estratégia de prevenção, ainda se faz presente. Entretanto, é importante considerar, que as matrizes de sentido devem assumir um diálogo amoroso e esclarecedor com os seus integrantes, pois eles clamam por uma 
educação em sexualidade responsável. A negligência e a ausência de diálogos pautados em evidências e comprometidos com a saúde sexual contemporânea é um importante aspecto que deve ser sanado em prol de uma melhor qualidade de vida afetivo-sexual de todos, e das pessoas que vivem com HIV, em particular.

Portanto, torna-se emergente que o Estado, como instituição responsável por fornecer acesso à informação, educação e saúde de qualidade aos brasileiros deve implementar, e/ou, resgatar as campanhas publicitárias de prevenção, como estratégia de trabalho dos setores que, de forma colaborativa e interdisciplinar possam, revisitar os "Programas de Saúde na Escola" e "Prevenção também se ensina", para instituir novas políticas públicas, a fim de corroborar com a erradicação do vírus HIV/AIDS, uma vez que a infecção continua em plena expansão.

\section{Referências}

ARRAES, G. R. d. A. Entre o desejo e a culpa: a transformação do comportamento sexual e as mudanças da noção de risco nas campanhas de prevenção à AIDS no Brasil ( $|98|-20 \mid 3)$ e Estados Unidos durante a década de 1980. Tese (Doutorado em História) - Universidade Federal de Santa Catarina, Florianópolis, 2015.

BARATA, G. F. "A primeira década da AIDS no Brasil: o Fantástico apresenta a doença ao público (1983 a 1992)". Dissertação (Mestrado em História) Universidade de São Paulo, São Paulo, 2006.

BARROS, S. G. de; VIEIRA-DA-SILVA, L. M. A gênese da política da AIDS e do espaço da AIDS no Brasil (I98I-1989). Revista de Saúde Pública, São Paulo, v. 50, n. 43, p. 12, 2016. Disponível em: http://www.scielo.br/scielo.php?script $=$ sci_ arttext\&pid=S0034-89 $|020| 6000|00227 \&| n g=e$ $\mathrm{n} \& \mathrm{nrm}=$ iso. Acesso em: 17 abr. 2020.

BASTOS, F. I. et al. The Hidden Face os AIDS in Brazil. Cadernos de Saúde Pública, Rio de Janeiro, v. 9, n. I, p. 90-96, jan./mar. 1993.

BRASIL. [Constituição (1988)]. Constituição da República Federativa do Brasil. Brasília, DF: Presidência da República, 1988. Disponível em: http://www.planalto.gov.br/ccivil_03/constituicao/ constituicao.htm. Acesso em: 27 abr. 2020.
BRASIL. Ministério da Saúde. Secretaria de Vigilância em Saúde. Programa Nacional de DST e AIDS. Diretrizes para implantação do Projeto Saúde e Prevenção nas Escolas. Brasília, DF: Ministério da Saúde, 2006. (Série A. Normas e Manuais Técnicos).

BRASIL. Ministério da Saúde. Boletim Epidemiológico de HIV e AIDS. Brasília, DF: Secretaria de Vigilância em Saúde: Departamento de Doenças de Condições Crônicas e Infecções Sexualmente Transmissíveis, 2019.

BRUNS. M. A. de T.; FERNANDES, Ítalo. Homossexuais soropositivos nos laços das relações amorosas. In: CONGRESSO BRASILEIRO DE SEXUALIDADE HUMANA, 17., 2019. Natal. Livro de Resumos [...]. Natal: Sociedade Brasileira de Estudos em Sexualidade Humana (SBRASH), 2019 . p. 50.

DUARTE, L. C. "A AIDS tem um rosto de mulher": discursos sobre o corpo e a feminização da epidemia. Tese (Doutorado em Antropologia Social) - Universidade Federal do Rio Grande do Sul, Porto Alegre, 2018.

DUARTE, R. de G. Sexo, sexualidade e doenças sexualmente transmissíveis. São Paulo: Moderna, 1995.

FORATTINI, O. P. AIDS e sua origem. Revista de Saúde Pública, São Paulo, v. 27, n. 3, p. I53-I56, jun. 1993. Disponível em: http://www.scielo. $\mathrm{br} / \mathrm{scielo}$.php?script $=$ sci_arttext\&pid $=$ S003489101993000300001 \&lng $=$ en\& $n r m=$ iso. Acesso em: 17 abr. 2020. https://doi.org/l 0.1590/ S0034-89I0I99300030000I.

FRANÇA, M. S. J. Ciência em tempos de AIDS: uma análise da resposta pioneira de São Paulo à epidemia. 2008. Tese (Doutorado em História da Ciência) - Pontifícia Universidade Católica de São Paulo, São Paulo, 2008.

LÚCIO, F. P. da S. et al. Saúde sexual da mulher lésbica e/ou bissexual: especificidades para o cuidado à saúde e educação sexual. Revista Ibero-Americana de Estudos em Educação, [S. I.], p. I465-I479, june 20 I9. Disponível em: https:// periodicos.fclar.unesp.br/iberoamericana/article/ view/I26 I I. Acesso em: I7 abr. 2020. 
MARQUES, M. C. da C. Saúde e poder: a emergência política da AIDS/HIV no Brasil. História, Ciências, Saúde-Manguinhos, Rio de Janeiro, v. 9, supl. p. 4I-65, 2002. Disponível em: http://www.scielo.br/scielo.php?script $=$ sci arttext\&pid $=$ SO I 04-59702002000400003\&Ing $=e$ $\mathrm{n} \& \mathrm{nrm}=$ iso. Acesso em: 17 abr. 2020.

MORA, C.; BRIGEIRO, M.; MONTEIRO, S. HIV Testing Among "MSM": Prevention Technologies, Sexual Moralities and Serologic Self-surveillance. Physis, Rio de Janeiro, v. 28, n. 2, e280204, 2018. Disponível em: http://www.scielo.br/ scielo.php?script $=$ sci_arttext\&pid $=$ SO I 03733 I 20 I $8000200600 \& \mid n g=e n \& n r m=i$ so. Acesso em: 27 fev. 2021 .http://dx.doi. org/I0.I590/s0I03-733I20I8280204.

NUNES, F. L. Como fazer revisão sistemática. São Paulo: USP, 20I5. I vídeo (2h38m04s). Publicado pelo Canal LARP MAE / USP. Disponível em: youtube.com/watch? $\mathrm{v}=$ Wgaw97mTKWM. Acesso em: 20 abr. 2020.

PAIVA, M. S. A feminilização da AIDS: uma questão de gênero? Revista Brasileira de Enfermagem, Brasília, v. 52, n. I, p. 7-I3, Mar. 1999. Disponível em: http://www.scielo. $\mathrm{br} /$ scielo.php?script $=$ sci_arttext\&pid $=$ S0034$7|67| 999000100002 \& \operatorname{lng}=$ en\& $\mathrm{nrm}=$ iso.

Acesso em: 17 abr. 2020.

SANABRIA, G. V. Ciência, estigmatização e afropessimismo no debate sul-africano sobre a AIDS. Vibrant: Virtual Brazilian Anthropology, Brasília, v. I3, n. I, p. 22-5I, jun. 20I6. Disponível em: http://www.scielo.br/scielo.php?script $=$ sci arttext\&pid =SI809-434 I $20|6000| 00022 \& \mid n g=e$ $\mathrm{n} \& \mathrm{nrm}=$ iso. Acesso em: 17 abr. 2020.

SANTOS, A. L. G. dos. Uma construção dos saberes sobre a epidemia de AIDS: os formulários de notificação de casos em perspectiva (198298). 1999. Dissertação (Mestrado em Saúde Pública) - Escola Nacional de Saúde Pública Sergio Arouca, Fundação Oswaldo Cruz, Rio de Janeiro, 1999.

SILVA, M. C. P. da. AIDS na cibercultura: a midiatização da doença nas redes sociais online do Ministério da Saúde. 20I2. Dissertação (Mestrado em Comunicação) - Universidade de Brasília, Brasília, 2012.
TREVISAN, J. S. Devassos no paraíso: a homossexualidade no Brasil, da colônia a atualidade. 4. ed. rev. atual. e amp. Rio de Janeiro: Objetiva, 2018.

TRINDADE, E.; BRUNS, M. A. de T. Sexualidade de jovens em tempos de AIDS. Campinas: Editora Átomo, 2003.

UMAN, L. S. Systematic Reviews and MetaAnalyses. Journal of the Canadian Academy of Child and Adolescent Psychiatry, v. 20, n. I, p. 57-59, 2011 .

WESTRUPP, M. H. B. Práticas sexuais de mulheres de parceiros infectados pelo HIV: contribuições acerca da cadeia epidemiológica da transmissão do HIV/AIDS. Tese (Doutorado em Filosofia de Enfermagem) - Universidade Federal de Santa Catarina. Florianópolis, 1997.

ZERBINATI, J. P.; BRUNS, M. A. T. Sexualidade e educação: revisão sistemática da literatura científica nacional. Travessias, v. II, n. I, p. 76-92, jan./abr. 2017. 